\title{
Maintainability improvement using allocation methods for railway systems
}

\author{
Marcantonio Catelani ${ }^{1}$, Lorenzo Ciani ${ }^{1}$, Giulia Guidi ${ }^{1}$, Gabriele Patrizi ${ }^{1}$ \\ ${ }^{1}$ University of Florence, Department of Information Engineering (DINFO), via di S. Marta 3, 50139, Florence, Italy
}

\section{ABSTRACT}

An optimal maintenance policy is an essential condition of many industrial products in terms of saving resources and minimising operational costs and system downtime. Some maintenance actions (e.g. corrective maintenance, preventive maintenance, and condition-based maintenance) are illustrated in the first part of this article. The article focuses on maintainability allocation techniques. Four procedures are analysed (the failure rate-based allocation method; the trade-off of failure rate and design feature-based allocation method; fuzzy maintainability allocation based on interval analysis; and the time characteristic-based MA model). Traditional procedures are characterised by several drawbacks; therefore, attention is given to the time characteristics-based method, which turned out to be the best and the most complete procedure because it does not have the limitations of the other methods. The last part of the article proposes a case study analysed using the techniques implemented in the maintainability allocation optimal method. Two different cases are studied. They differ in the mean time to repair objective. Initially, the requirement could vary inside a range, then, it is fixed to the value of six hours.

\section{Section: RESEARCH PAPER}

Keywords: maintainability, allocation, maintenance, complex system, Corrective Maintenance Downtime

Citation: Marcantonio Catelani, Lorenzo Ciani, Giulia Guidi, Gabriele Patrizi, Maintainability improvement using allocation methods for railway systems, Acta IMEKO, vol. 9, no. 1, article 3, March 2020, identifier: IMEKO-ACTA-09 (2020)-01-03

Editor: Lorenzo Ciani, University of Florence, Italy

Received October 30, 2019; In final form January 14, 2020; Published March 2020

Copyright: This is an open-access article distributed under the terms of the Creative Commons Attribution 3.0 License, which permits unrestricted use, distribution, and reproduction in any medium, provided the original author and source are credited.

Corresponding author: Giulia Guidi, e-mail: giulia.guidi@unifi.it

\section{INTRODUCTION}

Maintenance comprises all the techniques and management actions carried out during the useful period of a product in order to maintain it or restore it to a specific state with required functionality. Maintainability measures the ease and speed with which the system can be restored after a failure occurs [1]-[7].

Maintenance policies are divided into three categories:

- $\quad$ Corrective Maintenance (CM)

- $\quad$ Preventive Maintenance (PM)

- Condition-Based Maintenance (CBM)

In $\mathrm{CM}$, the maintenance task is actuated after a failure detection, whereas in PM, several periodic controls are implemented in order to avoid the presence of anomalies. CBM is similar to PM. It is focused on the prediction of a component degradation process and on the actions used to limit the wear of the component. The CBM technique is a maintenance strategy that uses certain procedures before the presence of product defeats, taking into account the operating context, the prediction of the failure effects, and the field data of similar products [8]$[10]$.
This work analyses how it is possible to achieve the maintainability improvement of complex systems using the Maintainability Allocation (MA) procedure. The main objective of the article is the study of the parameters included in the different MA techniques in order to identify the best procedure.

In the initial design phases of a project, MA is performed. MA is a process used to move a maintainability requirement at the system level (generally demanded by customers) into product specifications relative to the subsystems and single components (the procedure of item selection performed by the designer).

The purposes of MA techniques are:

- identifying the maintainability requirements for subsystems and items in order to guarantee the system maintainability requirements and goals; and

- focusing on maintainability complications during the design phase to ensure the assessment of requirements.

MA is an essential and convenient process used in product design, generally because all the projects start with well-defined and clear goals, and maintainability, as an intrinsic product characteristic, is determined in the design phase. 
Optimising the allocation procedure by using a reasonable apportion diagram, it is possible to minimise the environmental impact and the necessary resources, making the MA procedure as cheap as possible [11].

Since system failure is inevitable, quick system restorability is therefore the most important feature [11].

The main available methods for performing MA are the following:

- the equivalent allocation method;

- the failure rate-based allocation method;

- the trade-off of failure rate and design feature-based allocation method;

- the similar product maintainability data-based allocation method; and

- fuzzy MA based on interval analysis.

Considering a system composed of $n$ replaceable units, the mean corrective maintenance downtime $\bar{M}_{\mathrm{CT}}$ (also known as Mean Time to Repair [MTTR]) is evaluated using the following equation [12][13]:

$$
\bar{M}_{\mathrm{CT}}=\frac{\sum_{i=1}^{n} \bar{M}_{\mathrm{C} i} \lambda_{i}}{\sum_{i=1}^{n} \lambda_{i}}
$$

where $\lambda_{i}$ is the failure rate of the $i$-th element, and $\bar{M}_{\mathrm{C} i}$ is the system active corrective or repair downtime when the $i$-th item fails. When the designers implement a MA procedure, it is mandatory that the mean corrective maintenance downtime assessed for each item satisfies Equation 1. This issue could be solved using several different solutions, so the benefits and drawbacks of the proposed method must be considered in order to determine the most suitable result.

Usually, traditional allocation procedures neglect some important design factors (e.g. maintenance access channel). In this way, the mean corrective maintenance downtime allocated for every item could be not completely controlled, which is not allowed by the objectives of the allocation procedure [13].

In 2013, Dong et al. [14] overcame the drawbacks of traditional MA procedures, proposing an advanced method based on time parameters.

The following paragraph analyses three of the five previous methods. The equivalent allocation method and the similar product maintainability data-based allocation method were excluded because of their limited use.

\section{FAILURE RATE-BASED ALLOCATION METHOD}

This procedure allows an easy reconfiguration of the original system to optimise the components and subsystems maintainability. The equation provided from this method allows us to calculate the optimal Time to Repair (TTR) values to allocate for each item.

The principle of this allocation method is that the repair time allocated to the unit with the high failure rate is short and vice versa. The hypothesis of this method is that the allocated/ predicted values of reliability metrics already exist. The MTTR distributed to each unit is calculated as [14][15]:

$$
\bar{M}_{\mathrm{CT}_{i}}=\frac{\bar{M}_{\mathrm{CT}} \sum_{i=1}^{n} \lambda_{i}}{n \lambda_{i}}
$$

where $\bar{M}_{\mathrm{CT}_{i}}$ is the MTTR distributed to unit $i, \bar{M}_{\mathrm{CT}}$ is the MTTR of the system, $\lambda_{i}$ is the failure rate of unit $i$, and $n$ is the total number of unit types.

Not all units in an upgraded system need to be redesigned, because some of the units of the original system are adopted.
Assuming that an upgraded system is composed of $n$ subsystems, among which $L$ subsystems are the same as the starting system, the MA for the new layout follows this equation [14]:

$$
\bar{M}_{\mathrm{CT} j}=\frac{\bar{M}_{\mathrm{CT}} \sum_{i=1}^{n} \lambda_{i}-\sum_{i=1}^{L} \lambda_{i} \bar{M}_{\mathrm{CT}_{i}}}{(n-L) \lambda_{j}}
$$

where:

- $j=L+1, \ldots, n$;

- $\bar{M}_{\mathrm{CT}_{j}}$ is the MTTR for newly designed subsystem $j$;

- $\bar{M}_{\mathrm{CT}}$ is the MT'TR of the upgraded system;

- $\bar{M}_{\mathrm{CT}_{i}}$ is the MTTR of original subsystem $I$; and

- $\quad \lambda_{i}$ and $\lambda_{j}$ are the failure rates of subsystems $i$ and $j$, respectively.

The allocated maintainability indicators $\bar{M}_{\mathrm{CT}_{i}}$, based on the failure rates, are reasonable but may not be feasible. For example, one or several indicators could be extremely small and technically impossible to achieve. Indicators must be adjusted in case they require extreme technical solutions or very high costs (from an economic, time, and manpower point of view).

The various maintainability qualitative characteristics of the starting layout that influence repair time (e.g. complexity, accessibility, scalability, ease of replacement, and testability) must be considered, and a trade-off is the solution that determines the allocation results [16]-[18].

\section{TRADE-OFF OF THE FAILURE RATE- AND DESIGN FEATURE-BASED ALLOCATION METHODS}

Some relevant factors, such as complexity, accessibility, and testability, are transformed into weight coefficients when the allocation method, based on the trade-off of failure rate and the design features, is used [14].

The core structure of this method is similar to the previous one, but the introduction of weight factors offers more accuracy and allows the calculation of the importance of each factor within the MA procedure. The MTTR allocated to each unit is calculated as:

$$
\bar{M}_{\mathrm{CT}_{i}}=\beta_{i} \bar{M}_{\mathrm{CT}}
$$

where:

- $\bar{M}_{\mathrm{CT}_{i}}$ is the MTTR distributed to unit $I$;

- $\bar{M}_{\mathrm{CT}}$ is the MTTR of the system;

- $\beta_{i}=\frac{\bar{\lambda} k_{i}}{\lambda_{i} \bar{k}}$ is the weight coefficient of the repair time for the unit;

- $\bar{\lambda}=\frac{\sum_{i=1}^{n} \lambda_{i}}{n}$ is the average failure rate of each unit;

- $\bar{k}=\frac{\sum_{i=1}^{n} k_{i}}{n}$ is the average of each unit weight coefficient; and

- $k_{i}=\sum_{i=1}^{m} k_{i j}$ is the weight coefficient of factor $j$ in unit i.

The MA of the improved design subsystem is the following:

$$
\bar{M}_{\mathrm{CT}_{j}}=\frac{\bar{M}_{\mathrm{CT}} \sum_{i=1}^{n} \lambda_{i}-\sum_{i=1}^{L} \lambda_{i} \bar{M}_{\mathrm{CT}_{i}}}{\lambda_{j} \sum_{j=L+1}^{n} k_{j}} k_{j}
$$

where $j=L+1, \ldots n$.

The requirement for the maintainability design should be clear when this procedure is used. The weight coefficients in this method are the indices of the influencing factors for the maintainability indicators of each unit [14]. 
Many influencing factors should be used following this method, but it would be unacceptable in the case that different factors are taken into account without considering the differences of their effects; in addition, the values of the weighted factors need to be given directly. It is difficult to use a real number to describe the values of the weighted factors, since a little mistake could produce a serious error in the allocation outcomes. For this reason, two statements are mandatory: the weight value of every influencing factor is uncertain, and for a certain subsystem, the values of the weighted factors are also uncertain.

A piece of information associated with a single value is always incomplete, and it is subjected to errors that could make the results inaccurate. This problem is usually solved with an advanced method explained in section 4 [13].

\section{FUZZY MAINTAINABILITY ALLOCATION BASED ON INTERVAL ANALYSIS}

Fuzzy theory introduces the human mind logic to a binary logic system. Human reasoning admits the possibility of switching from one concept to another gradually, while this is not possible in the Boolean logic, where an element can only belong to a set (or not).

Fuzzy logic represents a deviation from the classic two-valued sets and logic. It uses 'soft' linguistic system variables (e.g. large, hot, and tall) and a continuous range of truth values in the interval $[0,1]$, rather than strict binary decisions and assignments ('True' or 'False').

Fuzzy rule-based systems apply these features to solve many types of 'real-world' problems, especially where a system is difficult to model, controlled by human operators or in case ambiguity or vagueness is common [19]-[21].

Before the allocation assessment, it is necessary to determine an index of maintainability. The most common maintainability parameters involve: MTTR, mean active PM time, mean active corrective maintenance time, maximum corrective maintenance time and maintenance downtime. MTTR is the fundamental metric, and it is widely used in repairable systems. It represents the average time required to repair a failed component or device. In other words, it is the total corrective maintenance time divided by the total number of corrective maintenance actions during a given period of time [22]-[24].

The index value should be determined after choosing the maintainability parameter. The following pieces of information are necessary to determine the maintainability index [13]:

- usage requirement;

- maintainability level of the similar products; and

- techniques supposed to be used.

Furthermore, factors such as reliability, life cycle cost, and product development should also be taken into account. The allocation model is based on a fuzzy comprehensive evaluation, as follows [25][26]:

$$
\widetilde{B}=\widetilde{W^{\circ}} \tilde{R}=\left[\begin{array}{llll}
w_{1} & w_{2} & \ldots & w_{m}
\end{array}\right]\left[\begin{array}{ccc}
r_{11} & \cdots & r_{1 n} \\
\vdots & \ddots & \vdots \\
r_{m 1} & \cdots & r_{m n}
\end{array}\right]
$$

$$
\tilde{B}=\left[\begin{array}{llll}
b_{1} & b_{2} & \ldots & b_{n}
\end{array}\right]
$$

where:

- $\widetilde{W}$ is the weight vector of the MA's influencing factors;

- $\quad \tilde{R}$ is the matrix of the subsystems' influencing factors;

- $\tilde{B}$ is the result of the maintainability comprehensive evaluation;
- $b_{1}, b_{2}, \ldots b_{n}$ express the relative values of the maintainability weight factor of each subsystem;

- $\quad$ the symbol ${ }^{\circ}$ is the fuzzy composition operator;

- $m$ is the number of influencing factors; and

- $\quad n$ is the number of subsystems [27].

In the fuzzy procedure, the MA process is as follows [13]:

- $\quad$ Step 1: Synthetically calculate the original image $\widetilde{W}$ by means of interval analysis and analytic hierarchy process (AHP);

- $\quad$ Step 2: Calculate the mapping $\widetilde{R}$; and

- $\quad$ Step 3: Draw image $\tilde{B}$ by means of fuzzy mapping.

After determining the set of influencing factors of MA, it is necessary to determine the weight of each factor, and there are various methods of doing so.

The most used are listed below:

- The AHP could combine qualitative analysis and quantitative analysis. This combined method is widely used in the decision-making for and evaluation of complex systems, and the weight of each attribute is acquired by a pair-wise comparison matrix [28]-[30];

- The Delphi method uses experts' direct weighting. Each of them gives a weight value by their experience, and then the average value is taken as the weight [31].

Many methods can be used to determine the element of vector $\widetilde{B}$, and the maintainability allocation can be written as follows:

$$
\bar{M}_{\mathrm{CT}_{j}}=\frac{b_{j} \sum_{j=1}^{n} \lambda_{j}}{\sum_{j=1}^{n} \lambda_{j} b_{j}} \bar{M}_{\mathrm{CT}}
$$

\section{TIME CHARACTERISTICS-BASED MAINTAINABILITY ALLOCATION MODEL FOR COMPLEX EQUIPMENT}

Usually, in company policies, various design departments monitor different items; therefore, the repair time must be divided into two categories [14][32]:

- The common repair time $T_{\mathrm{CMN}}$ is determined by the overall design or upper-level department, and it is not directly affected and controlled by product design at this stage.

- The individual repair time $T_{\text {IDV }}$ is the repair time determined by product design, such as assembly, changing, and adjustment time.

Considering that the formation mechanisms of the different types of maintenance time are different, the types of maintenance time are influenced and controlled by different product design departments.

Some influencing factors must be evaluated in order to assess the repair time of the system. The time characteristics-based MA model identifies two different allocation levels (high and low) and two different respective allocation procedures [33].

The high-level procedure considers a system with $n$ subsystems, characterised by the respectively failure rates $\lambda_{1}, \lambda_{2}, \ldots \lambda_{n}$.

Using Equation 9, it is possible to evaluate the common repair time $T_{\mathrm{CMN}}$ :

$T_{\mathrm{CMN}}=T_{\mathrm{P}}+T_{\mathrm{A}}+T_{\mathrm{R}}$

where $T_{\mathrm{P}}$ is the maintenance preparation time, $T_{\mathrm{A}}$ is the approaching time, and $T_{\mathrm{R}}$ is the final reassembly time [9]. 
The method of determining $T_{\mathrm{P}}$ is similar to the product ratio method. If the MTTR of the designing product is $\bar{M}_{\mathrm{CT}}, \bar{M}_{\mathrm{CT}}^{\prime}$ and $T^{\prime}{ }_{\mathrm{P}}$ are respectively the MTTR and preparation time for similar products, the preparation time for designing the product is [34]:

$$
T_{\mathrm{P}}=\frac{\bar{M}_{\mathrm{CT}}}{\bar{M}_{\mathrm{CT}}^{\prime}} T_{\mathrm{P}}^{\prime}
$$

The common repair time is divided into three parts, and in a generic manufacturing application, the time intervals are the following: the time spent opening the flap of the access channel $\left(T_{\mathrm{A} 1}\right)$, the time spent moving and accessing the cabin that requires repair $\left(T_{\mathrm{A} 2}\right)$, and the time spent opening the fasteners and removing the obstacles near the replacement unit $\left(T_{\mathrm{A} 3}\right)$. The approaching time $T_{\mathrm{A}}$ is [14]:

$$
T_{\mathrm{A}}=T_{\mathrm{A} 1}+T_{\mathrm{A} 2}+T_{\mathrm{A} 3}
$$

The approaching time is not equal to zero when the system shares the maintenance access channel; however, when each item has its own maintenance access channel, the approaching time belonging to the common repair time is zero.

Similar to the approaching time, the reassembly time is controlled by the overall sector or the upper-level design department, and it is affected by the same factors that affect the approaching time. Thus, $T_{\mathrm{R}}$ is:

$$
T_{\mathrm{R}}=T_{\mathrm{A}}
$$

The individual repair time is calculated by eliminating the common repair time from the MTTR of the whole system [34].

$$
T_{\text {IDV }}=\bar{M}_{\mathrm{CT}}-T_{\mathrm{CMN}}
$$

Then, according to the failure rate-based allocation method, the repair time of each subsystem can be evaluated as follows:

$$
\bar{M}_{\mathrm{CT} i}=\frac{\sum_{i=1}^{n} \lambda_{i}}{n \lambda_{i}} T_{\mathrm{IDV}}=\frac{\bar{\lambda}}{\lambda_{i}} T_{\mathrm{IDV}}
$$

where $\bar{M}_{\mathrm{CT} i}$ is the repair time allocated to subsystem $i, \lambda_{i}$ is the failure rate of subsystem $i$, and $\bar{\lambda}=\frac{\sum_{i=1}^{n} \lambda_{i}}{n}$ is the average failure rate of all subsystems. For a system consisting of $n$ subsystems, where $L$ of them $(L<n)$ are existing products, the maintainability indicators of the newly designed subsystems are allocated as follows [14]:

$$
\bar{M}_{\mathrm{CT} j}=\frac{T_{\mathrm{IDV}} \sum_{i=1}^{n} \lambda_{i}-\sum_{i=1}^{L} \lambda_{i} \bar{M}_{\mathrm{CT} i}}{\lambda_{j}(n-L)} k_{j}
$$

Isolation, disassembly, and replacement are included in the maintenance procedure for low-level items. The time needed for these three actions is included into the individual repair time. Finally, considering the low-level components, the individual repair time is given by [14]:

$$
T_{\mathrm{RU}-\mathrm{IDV}}=\bar{M}_{\mathrm{CT} i}-T_{\mathrm{RU}-\mathrm{CMN}}
$$

where:

- $T_{\mathrm{RU}-\mathrm{IDV}}$ is the individual repair time allocated to the single Replaceable Unit (RU);

- $\bar{M}_{\mathrm{CT} i}$ is the time indicator allocated to subsystem $i$ from the system level using the high-level product allocation model; and

- $\quad T_{\mathrm{RU}-\mathrm{CMN}}$ is the common repair time in this level.

The equipment replacement procedure should be considered in the late development stage to improve the precision of allocation.

When a failure is isolated to a single RU, the RU can be replaced individually to correct the fault. If the failure is isolated to an RU group and the RUs in the group are irrelevant, the group can be considered as a single RU. The group in which the RUs are replaced alternately is denoted as $R U_{\mathrm{GE}}$. The group in which the RUs are all replaced is denoted as $R U_{\mathrm{GA}}$.

The MA procedure involves the allocation of the system MTTR to $R U_{1}, \ldots R U_{j}, R U_{\mathrm{GE}_{1}}, \ldots R U_{\mathrm{GE}_{k}}, R U_{\mathrm{GA}_{1}}, \ldots R U_{\mathrm{GA}_{l}}$ according to the failure and design features of each RU or RU group.

Considering an RU group composed by $m$ single RUs, the average number of replacements $S_{i}$ is:

$$
S_{i}=\left[\frac{m+1}{2}\right]
$$

where the symbol $[x]$ means the maximum integer not larger than $x$.

In this study, six kinds of maintainability design features are considered: fault detection and isolation; maintenance channel; fasteners; internal assembly; replacement; and scalability. These features may be different among different products depending on specific circumstances. The repair time differs because different maintenance schemes are employed. In order to increase the reasonability and accuracy of the MA procedure, this method considers a new coefficient $\alpha_{i}$. There are three different cases [14]:

- If the failure is isolated to a single RU, the correct coefficient is $\alpha_{i}=1$;

- If the failure is isolated to an RU group consisting of $m$ replaced alternately $\alpha_{i}=S_{i}=\left[\frac{m+1}{2}\right]$; and

- If the failure is isolated to an RU group consisting of $r$ and all are replaced, the correct coefficient is $\alpha_{i}=r$;

using the following equation, the repair time allocated to each RU can evaluated:

$$
\bar{M}_{\mathrm{CT} i}=\frac{k_{i}^{\prime} \sum_{i=1}^{j+k+l} \lambda_{i}}{\lambda_{i} \sum_{i=1}^{j+k+l} k_{i}^{\prime}} T_{\mathrm{RU}-\mathrm{IDV}}
$$

where:

- $k_{i}^{\prime}=\alpha_{i} k_{i}=\alpha_{i} \sum_{j=1}^{m} k_{i j}$ with $m$ number of weight coefficients and $k_{i j}$ weight coefficient of factor $j$ in unit $i$

- $\quad i=1, \ldots, j, j+1, \ldots, j+k, j+k+1, \ldots, j+k+l$

For the reconfigured system, the maintainability indicators of the newly designed subsystems are allocated as follows:

$$
\bar{M}_{\mathrm{CT} j}=\frac{T_{\mathrm{RU}-\mathrm{IDV}} \sum_{i=1}^{j+k+l} \lambda_{i}-\sum_{i=1}^{L} \lambda_{i} \bar{M}_{\mathrm{CT} i}}{\lambda_{i} \sum_{j=L+1}^{n} k_{j}^{\prime}} k_{j}^{\prime}
$$

where $j=L+1, \ldots n$.

Figure 1 highlights the main stages of the time characteristicsbased MA procedure. Initially, the high-level procedure allocates the MTTR to the RU group, meaning the subsystem level. In the second step, the mean corrective downtime of every single Level Replaceable Unit (LRU) is evaluated using the low-level method.

\section{COMPARISON OF THE METHODS}

MA is considered a vital process in the design phase of a new system, since the optimal allocation of maintainability indicators to the various subsystems of a complex system has many advantages.

Obviously, each MA procedure is required to satisfy the system maintainability objective. 


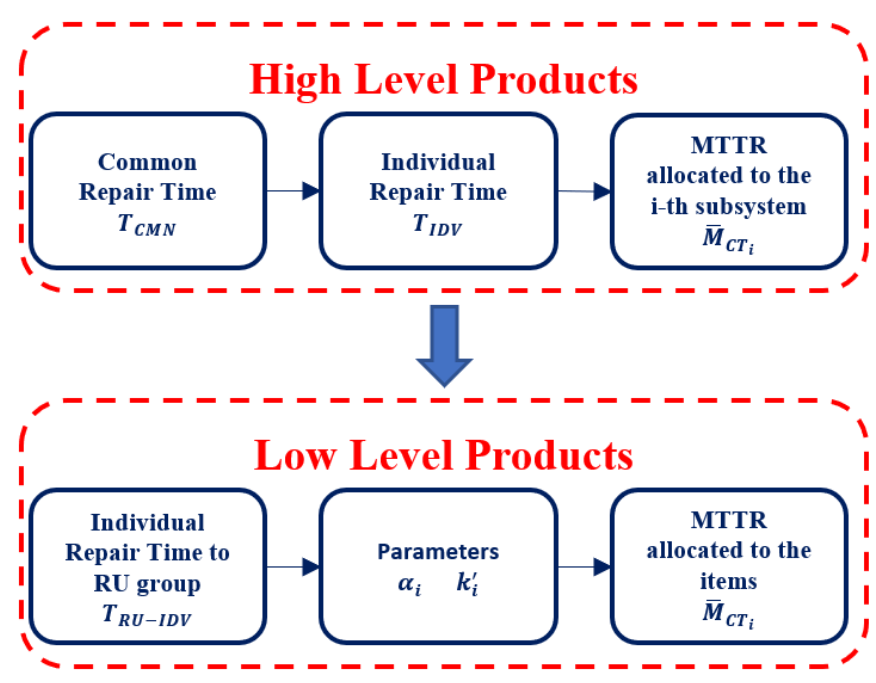

Figure 1. Time Characteristic-Based Ma Method Flow-Chart

Once the allocation target is defined, it is mandatory to plan a series of system interventions, reconfigurations, and corrections in order to optimise maintenance activities, as well as reducing their implementation costs and their impact on society and the environment.

In the previous sections, four MA methods were analysed and compared to bring out their characteristics, strengths, and weaknesses and to identify which is the optimal method for the application under analysis.

The failure rate-based allocation method is a basic procedure for MA assessment. It is easy and fast to apply and is based on the resolution of elementary mathematic equations. In any case, an intrinsic limit is hidden in this method: the designer must know beforehand the overall system MTTR and the failure rates of each single unit. This procedure is not widely used due to the lack of precision and accuracy because it does not consider the number of influencing factors, which deeply affects maintenance activities.

The trade-off between the failure rate- and design featurebased allocation methods solves the problems explained previously, but it also introduces some other issues. Some influencing factors, particularly complexity, accessibility, and scalability, are taken into account using dedicated weight coefficients that reflect each role in the maintenance process; however, this solution has some disadvantages: it is necessary to know in advance a great number of parameters, and the final results profoundly vary if the evaluation is not accurate. Another problem is the inability to differentiate the influencing factors depending on the nature of their effects, and this is not acceptable.

The fuzzy MA based on interval analysis method was introduced because a weight factor, assigned as a real number, cannot fully describe the real scenario. In this procedure, a real number is replaced by an interval of real numbers in order to build a judgement matrix. The method combines fuzzy theory, interval analysis, testing data, and expert judgement. This MA procedure is characterised by a high implementation complexity and a significant waste of budget, resource, and time.

Therefore, attention is given to the last method, which turned out to be the best and the most complete because it exceeds the other methods' limitations. Indeed, the time characteristicsbased MA method is practical, quick and easy to implement, and provides satisfying results. The relationship between the project and the repair time is taken into account, and time is divided into common and individual repair time. The first type is deducted from the total system repair time, while the second is allocated to specific units using one of the traditional methods. The following pieces of information are required to apply this procedure: system structure and corresponding hierarchical levels, the information about the RU, and the overall system MTTR (the goal of the allocation procedure).

\section{CASE STUDY}

Redundancy increases system reliability leading to a fault tolerance design [35]-[38]. It is widely used in many technological fields, such as energy production [39]-[41] and transportation [42], [43]. In particular, redundancy is a mandatory design tool in railway applications, because the functional safety constraints demanded by the international railway standards [44]-[46] require that the system continues to perform its tasks also in case of failure, occasionally with less functionality, instead of failing completely [23][24][47].

A generic complex system, including redundant configurations, has been studied in order to analyse the time characteristics-based MA procedure (Figure 2). The system under test is an electronic controller included in many safetyrelated systems used for railway signalling. In such systems, an optimised maintenance plan is able to reduce the overall operational costs, leading to a reduction in the waste of resources.

The input of the MA procedure is the system's MTTR. In order to obtain the maximum system Reliability, Availability, and Maintainability (RAM) performance, in the first case, the system MTTR could vary inside the interval $(1 \mathrm{~h}-8 \mathrm{~h})$.

Table 1 shows the failure rates of the components related to the reliability block diagram in Figure 2. Table 2 contains the input and output of the low-level allocation procedure.

In order to distribute the MTTR in the RU group level, the following equation is used:

$T_{\mathrm{CMN}}=T_{\mathrm{P}}+T_{\mathrm{A}}+T_{\mathrm{R}}=2.5 \mathrm{~h}$.

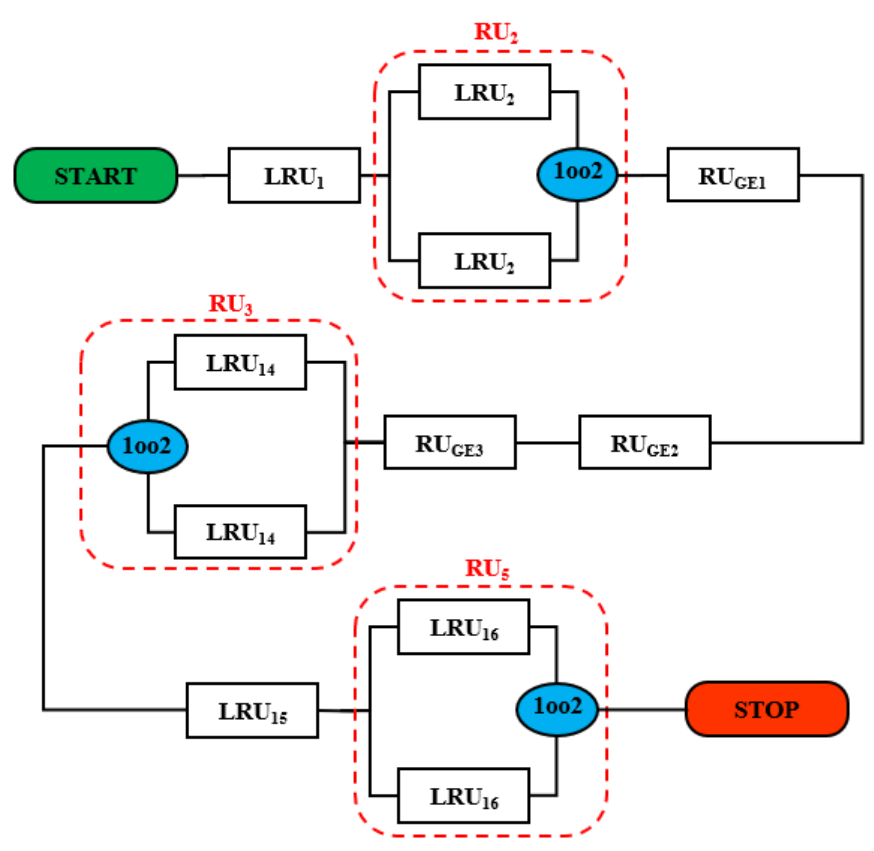

Figure 2. Reliability Block Diagram (RBD) of the system under test. 
Table 1. Failure rates of the components included in the RBD of the control system under analysis

\begin{tabular}{|c|c|c|c|}
\hline RU group & LRU Code & $\lambda_{\text {LRU }}[\mathrm{FIT}]$ & $\lambda_{\mathrm{RU}}[\mathrm{FIT}]$ \\
\hline $\mathrm{RU}_{1}$ & $\mathrm{LRU}_{1}$ & 956.4 & 956.4 \\
\hline $\mathrm{RU}_{2}$ & $\mathrm{LRU}_{2}$ & 510 & 510 \\
\hline \multirow{4}{*}{$\mathrm{RU}_{\mathrm{GE1}}$} & $\mathrm{LRU}_{3}$ & 1422 & \multirow{4}{*}{3994} \\
\hline & $\mathrm{LRU}_{4}$ & 704 & \\
\hline & $\mathrm{LRU}_{5}$ & 1595 & \\
\hline & $\operatorname{LRU}_{6}$ & 273 & \\
\hline \multirow{4}{*}{$\mathrm{RU}_{\mathrm{GE} 2}$} & $\mathrm{LRU}_{7}$ & 1422 & \multirow{4}{*}{3994} \\
\hline & $\mathrm{LRU}_{8}$ & 704 & \\
\hline & $\mathrm{LRU}_{9}$ & 1595 & \\
\hline & $\operatorname{LRU}_{10}$ & 273 & \\
\hline \multirow{3}{*}{$\mathrm{RU}_{\mathrm{GE3}}$} & $\operatorname{LRU}_{11}$ & 140 & \multirow{3}{*}{924} \\
\hline & $\operatorname{LRU}_{12}$ & 392 & \\
\hline & $\operatorname{LRU}_{13}$ & 392 & \\
\hline $\mathrm{RU}_{3}$ & $\operatorname{LRU}_{14}$ & 387.7 & 387.7 \\
\hline $\mathrm{RU}_{4}$ & $\mathrm{LRU}_{15}$ & 1700 & 1700 \\
\hline $\mathrm{RU}_{5}$ & $\operatorname{LRU}_{16}$ & 387.7 & 387.7 \\
\hline
\end{tabular}

Feedback and field data have been used to determine the time values. In compliance with Equations 13 and 14, $T_{\mathrm{IDV}}=$ $1.5 \mathrm{~h}$ and $\bar{M}_{\mathrm{CT}_{\mathrm{SYS}}}=M T T R_{\mathrm{SYS}}=4 \mathrm{~h}$. The overall MTTR is acceptable because it belongs to the objective MTTR range $(1 \mathrm{~h}$ $8 \mathrm{~h})$.

In order to allocate the MTTR of the LRU level, the objective is $\bar{M}_{\mathrm{CT}_{\mathrm{SYS}}}=M T T R_{\mathrm{SYS}}=4 \mathrm{~h}$. In compliance with Equation 9, the common repair times are listed in Table 2.

Based on Equations 10 to 14, the MTTR of the RU groups are listed in Table 3.

According to Equation 16 and using the method described in paragraph III, it is possible to calculate the MTTR of each element (LRU); the results are shown in Table 4.

A second case study (Case B) has been analysed to investigate the possible changes of the procedural outcomes caused by some input changes. The objective of this study is to underline the relationship between the maintenance index allocated using this method and the overall MTTR requirement of the control system under test used in railway applications.
Table 2. Low-level allocation

\begin{tabular}{|c|c|c|c|c|c|c|c|}
\hline RU group & LRU Code & $S_{i}$ & $\alpha_{i}$ & $K_{i \text {-LRU }}$ & $K_{i-\mathrm{RU}}$ & $K_{i}^{\prime}$ & $T_{\mathrm{RU}-\mathrm{CMN}}$ in $\mathrm{h}$ \\
\hline $\mathrm{RU}_{1}$ & $\mathrm{LRU}_{1}$ & 1 & 1 & 8 & 8 & 8 & 0 \\
\hline $\mathrm{RU}_{2}$ & $\mathrm{LRU}_{2}$ & 1 & 1 & 8 & 8 & 8 & 0 \\
\hline $\mathrm{RU}_{\mathrm{GE} 1}$ & $\begin{array}{l}\mathrm{LRU}_{3} \\
\mathrm{LRU}_{4} \\
\mathrm{LRU}_{5} \\
\mathrm{LRU}_{6}\end{array}$ & 2 & 2 & $\begin{array}{l}14 \\
16 \\
20 \\
12\end{array}$ & 16 & 32 & 1.33 \\
\hline $\mathrm{RU}_{\mathrm{GE2}}$ & $\begin{array}{l}\mathrm{LRU}_{7} \\
\mathrm{LRU}_{8} \\
\mathrm{LRU}_{9} \\
\mathrm{LRU}_{10}\end{array}$ & 2 & 2 & $\begin{array}{l}14 \\
16 \\
20 \\
12\end{array}$ & 16 & 32 & 1.33 \\
\hline $\mathrm{RU}_{\mathrm{GE3}}$ & $\begin{array}{l}\operatorname{LRU}_{11} \\
\operatorname{LRU}_{12} \\
\operatorname{LRU}_{13}\end{array}$ & 2 & 2 & $\begin{array}{l}16 \\
12 \\
12\end{array}$ & 12 & 24 & 1.5 \\
\hline $\mathrm{RU}_{3}$ & $\operatorname{LRU}_{14}$ & 1 & 1 & 8 & 8 & 8 & 0 \\
\hline $\mathrm{RU}_{4}$ & $\operatorname{LRU}_{15}$ & 1 & 1 & 8 & 8 & 8 & 0 \\
\hline $\mathrm{RU}_{5}$ & $\mathrm{LRU}_{16}$ & 1 & 1 & 8 & 8 & 8 & 0 \\
\hline
\end{tabular}

Table 3. MTTR allocated to the RU groups.

\begin{tabular}{|c|c|c|c|c|c|c|c|}
\hline $\mathrm{RU}_{1}$ & $\mathrm{RU}_{2}$ & $\mathrm{RU}_{\mathrm{GE} 1}$ & $\mathrm{RU}_{\mathrm{GE} 2}$ & $\mathrm{RU}_{\mathrm{GE} 3}$ & $\mathrm{RU}_{14}$ & $\mathrm{RU}_{15}$ & $\mathrm{RU}_{16}$ \\
\hline $3 h 22^{\prime}$ & 6h18' & 3h13' & 3h13' & $10 \mathrm{~h} 26^{\prime}$ & 8h17' & 1h53' & 8h17' \\
\hline
\end{tabular}

The overall MTTR objective in Case B is 6 hours, which is higher than the previous case. The results are reported in Table 5. Based on a comparison between Table 4 and Table 5, the high values of the MTTR objective correspond with the high values of the single MTTR parameters allocated to the items. Figure 3 shows the differences between MTTR in different cases.

The component characterised by the highest MTTR (i.e. the most critical item) is $L R U_{11}$ with an allocated MTTR of $23 \mathrm{~h} 53$ $\mathrm{m}$. The items characterised by the lowest MTTR (i.e the least critical equipment) are $L R U_{3}, L R U_{5}, L R U_{7}$, and $L R U_{9}$ with an allocated MTTR of approximately $1 \mathrm{~h}$.

The values collected in Table 5 result increased. The percentage deviations of the less critical items are more significant, and they surpass $100 \%$ for $L R U_{3}$ and $L R U_{7}$.

Table 4. MA procedure output for a complex system in Case A.

\begin{tabular}{|c|c|c|c|c|c|c|c|c|c|c|c|c|c|c|c|c|}
\hline & $\operatorname{LRU}_{1}$ & $\mathrm{LRU}_{2}$ & $\mathrm{LRU}_{3}$ & $\mathrm{LRU}_{4}$ & $\mathrm{LRU}_{5}$ & $\operatorname{LRU}_{6}$ & $\mathrm{LRU}_{7}$ & $\operatorname{LRU}_{8}$ & $\mathrm{LRU}_{9}$ & $\operatorname{LRU}_{10}$ & $\operatorname{LRU}_{11}$ & $\operatorname{LRU}_{12}$ & $\operatorname{LRU}_{13}$ & $\operatorname{LRU}_{14}$ & $\operatorname{LRU}_{15}$ & $\operatorname{LRU}_{16}$ \\
\hline$M_{T T R}$ & $3 h 22^{\prime}$ & $6 h 18^{\prime}$ & $1 \mathrm{~h} 12^{\prime}$ & $2 \mathrm{~h} 46^{\prime}$ & $1 \mathrm{~h} 31^{\prime}$ & $5 h 20^{\prime}$ & $1 \mathrm{~h} 12^{\prime}$ & $2 \mathrm{~h} 46^{\prime}$ & $1 \mathrm{~h} 31^{\prime}$ & $5 \mathrm{~h} 20^{\prime}$ & $23 h 35^{\prime}$ & 6h19' & 6h19' & $8 \mathrm{~h} 17^{\prime}$ & $1 \mathrm{~h} 53^{\prime}$ & 8h17' \\
\hline
\end{tabular}

Table 5. MA procedure output for complex system in Case B.

\begin{tabular}{|c|c|c|c|c|c|c|c|c|c|c|c|c|c|c|c|c|}
\hline & $\operatorname{LRU}_{1}$ & $\mathrm{LRU}_{2}$ & $\mathrm{LRU}_{3}$ & $\operatorname{LRU}_{4}$ & $\mathrm{LRU}_{5}$ & $\operatorname{LRU}_{6}$ & $\operatorname{LRU}_{7}$ & $\operatorname{LRU}_{8}$ & $\mathrm{LRU}_{9}$ & $\operatorname{LRU}_{10}$ & $\operatorname{LRU}_{11}$ & $\operatorname{LRU}_{12}$ & $\operatorname{LRU}_{13}$ & $\operatorname{LRU}_{14}$ & $\operatorname{LRU}_{15}$ & $\operatorname{LRU}_{16}$ \\
\hline$M_{T T R}$ & $5 \mathrm{~h} 22^{\prime}$ & 9h27' & $2 \mathrm{~h} 30^{\prime}$ & $4 h 45^{\prime}$ & $2 \mathrm{~h} 37^{\prime}$ & 9h11' & $2 \mathrm{~h} 30^{\prime}$ & $4 h 45^{\prime}$ & $2 \mathrm{~h} 37^{\prime}$ & 9h11' & $36 h 29^{\prime}$ & $9 h 46^{\prime}$ & 9h46' & $12 \mathrm{~h} 26^{\prime}$ & $2 \mathrm{~h} 50^{\prime}$ & $12 \mathrm{~h} 26^{\prime}$ \\
\hline
\end{tabular}




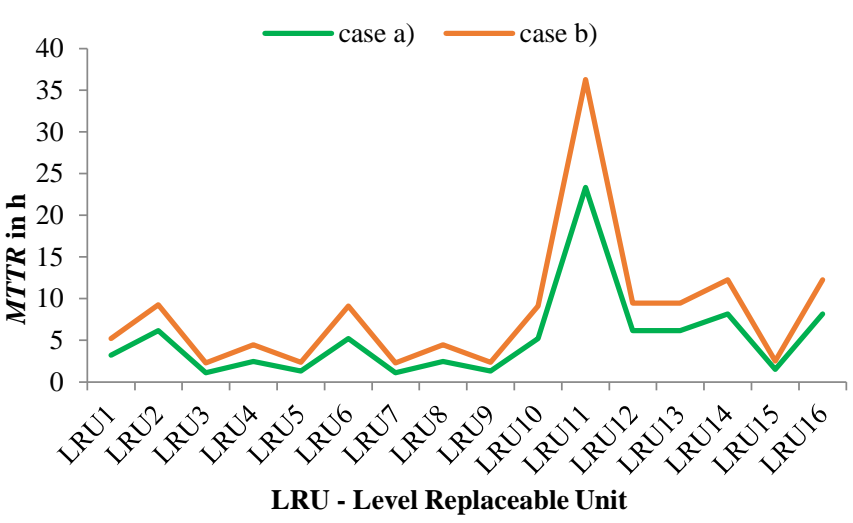

Figure 3. Comparison of the two cases.

Figure 4 depicts the difference between the two cases relative to the maximum MTTR value obtained in the first analysis $\left(\mathrm{LRU}_{11}\right)$. The maximum deviation is associated with the most critical elements.

\section{CONCLUSION}

Initially, this article illustrated the different aspects of the maintenance policies by focusing on maintainability assessment. Starting from a study of four allocation methods, this article proposed the time characteristics-based maintainability assessment technique as the optimal procedure, because it could weigh the influence of every item on the system parameters.

Maintainability assessment during the design stage represents one of the most important phases in making structural decisions and selecting the best items needed to complete the mission: this feature is a huge improvement in industrial applications because design can be based on a maintainability assessment.

In particular, an electronic controller for a railway signalling system has been studied. In the initial part of the study, the objective was $M T T R_{\text {SYS }} \in[1 \mathrm{~h}-8 \mathrm{~h}]$ and the obtained result was $M T T R_{\mathrm{SYS}}=4 \mathrm{~h}$. Then, the overall MTTR has been increased up to $6 \mathrm{~h}$. A comparison between the two cases highlights that by increasing the objective MTTR, the maintainability indices allocated to the items increase. Considering the most critical components, a high objective MTTR allows a significant increase in the common repair time.

\section{REFERENCES}

[1] MIL-HDB-338B, Electronic Reliability Design Handbook. US Department of Defense, Washington DC, 1998.

[2] A. Birolini, Reliability Engineering ( $7^{\text {th }}$ ed.) Springer Berlin Heidelberg, Berlin, Heidelberg, 2014.

[3] K. A. Kaiser, N. Z. Gebraeel, Predictive Maintenance Management Using Sensor-Based Degradation Models, IEEE Trans. Syst. Man, Cybern. - Part A Syst. Humans 39(4) (2009) pp. 840-849.

[4] F. Chen, H. Zhang, B. Xu, X. Chen, Z. Yang, Y. Ye, Q. Xie, Research on Imperfect Preventive Maintenance Strategy for Turret System of the CNC Lathe, in Proc. of the 11th International Conference on Reliability, Maintainability and Safety (ICRMS), 2016, pp. 1-4.

[5] United States Department of Defense, MIL-STD-721C Definitions of Terms for Reliability and Maintainability, 1981.

[6] E. de Francesco, F. Leccese, Risks Analysis for Already Existent Electric Lifelines in Case of Seismic Disaster, in Proc. of the 11th

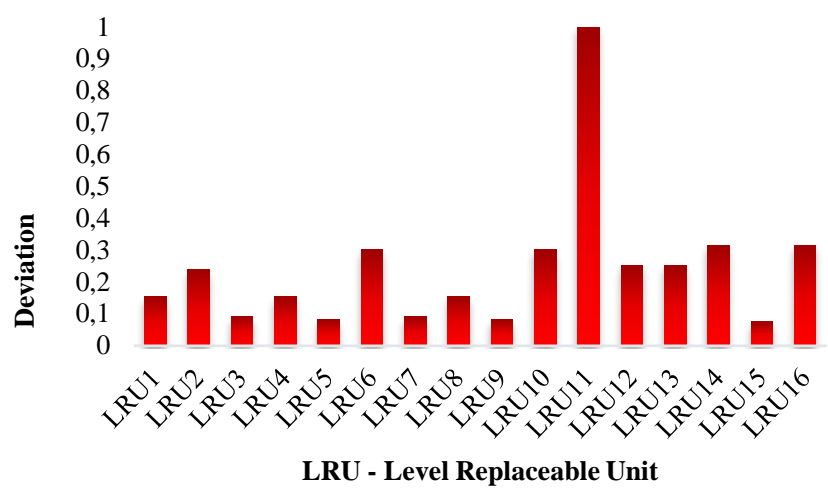

Figure 4. Relative deviation between the two cases

International Conference on Environment and Electrical Engineering, 2012, pp. 830-834.

[7] E. Petritoli, F. Leccese, L. Ciani, Reliability and Maintenance Analysis of Unmanned Aerial Vehicles, Sensors 18(9) (2018) p. 3171.

[8] M. Khalil, C. Laurano, G. Leone, M. Zanoni, Outage Severity Analysis and RAM Evaluation of Italian Overhead Transmission Lines from a Regional Perspective, Acta IMEKO 5(4) (2016) pp. 73-79.

[9] T. Addabbo, A. Fort, C. Della Giovampaola, M. Mugnaini, A. Toccafondi, V. Vignoli, On the Safety Design of Radar Based Railway Level Crossing Surveillance Systems, Acta IMEKO 5(4) (2016) pp. 64-72.

[10] A. Reatti, M. K. Kazimierczuk, M. Catelani, L. Ciani, Monitoring and Field Data Acquisition System for Hybrid Static Concentrator Plant, Measurement 98 (2017) pp. 384-392.

[11] L. Chen, J. Cai, Using Vector Projection Method to Evaluate Maintainability of Mechanical System in Design Review, Reliab. Eng. Syst. Saf. 81(2) (2003) pp. 147-154.

[12] Department of Defense, AMCP 706-133, Maintainability Engineering Theory and Practice, Washington, 1976.

[13] Q. Hao, Z. Yang, F. Chen, B. Xu, X. Li, C. Chen, A Fuzzy Maintainability Allocation Method for NC Machine Tools Based on Interval Analysis, Proc. of the 9th International Conference on Reliability, Maintainability and Safety, ICRMS 2011, pp. 889-896.

[14] D. Zhou, X. Jia, C. Lv, Y. Li, Maintainability Allocation Method Based on Time Characteristics for Complex Equipment, Maint. Reliab. 15(4) (2013) pp. 441-448.

[15] A. Paggi, G. L. Mariotti, R. Paggi, A. Calogero, F. Leccese, Prediction by Means Hazard Rate Occurrence is a Deeply Wrong Approach, Proc. of the IEEE International Workshop on Metrology for AeroSpace (MetroAeroSpace), 2017, pp. 276-281.

[16] P. Moreu de Leon, V. González-Prida Díaz, L. Barberá Martínez, A. Crespo Márquez, A Practical Method for the Maintainability Assessment in Industrial Devices Using Indicators and Specific Attributes, Reliab. Eng. Syst. Saf. 100 (2012) pp. 84-92.

[17] X. F. Zha, H. Du, Knowledge-Intensive Collaborative Design Modeling and Support: Part II: System Implementation and Application, Comput. Ind., 2006.

[18] E. de Francesco, R. de Francesco, F. Leccese, Use of the ASD S3000L for the Optimization of Projects in order to Reduce the Risk of Obsolescence of Complex Systems, Proc. of the IEEE 5th International Workshop on Metrology for AeroSpace (MetroAeroSpace), 2019, pp. 233-237.

[19] L. A. Zadeh, Fuzzy Sets, Inf. Control 8(3) (1965) pp. 338-353.

[20] L. A. Zadeh, Outline of a New Approach to the Analysis of Complex Systems and Decision Processes, IEEE Trans. Syst. Man. Cybern. SMC-3(1) (1973) pp. 28-44.

[21] E. Rico Petritoli, F. Leccese, M. Cagnetti, Takagi-Sugeno Discrete Fuzzy Modeling: an IoT Controlled ABS for UAV, Proc. of the II Workshop on Metrology for Industry 4.0 and IoT (MetroInd4.0\&IoT), 2019, pp. 191-195. 
[22] Department of Defense, Military Handbook 472: Maintenance Prediction, May 1966.

[23] M. Rausand, A. Hoyland, System Reliability Theory (2 ${ }^{\text {nd }}$ ed.) John Wiley \& Sons Inc., 2004.

[24] R. F. Stapelberg, Handbook of Reliability, Availability, Maintainability and Safety in Engineering Design, Springer London: London, 2009.

[25] M. Kwiesielewicz, A Note on the Fuzzy Extension of Saaty's Priority Theory, Fuzzy Sets Syst. 95(2) (1998) pp. 161-172.

[26] H. Yu, G. Peng, W. Liu, A Practical Method for Measuring Product Maintainability in a Virtual Environment, Assem. Autom. 31(1) (2011) pp. 53-61.

[27] P. J. M. van Laarhoven, W. Pedrycz, A Fuzzy Extension of Saaty's Priority Theory, Fuzzy Sets Syst. 11(1-3) (1983) pp. 229-241.

[28] G.-L. Lee, H.-J. Lin, T.-W. Yu, J.-Y. Chen, C.-C. Ma, S.-L. Chyou, Optimal Allocation for Improving System Reliability Using AHP, Proc. of the IEEE International Conference on Sustainable Energy Technologies, No. 1, 2008, pp. 159-163.

[29] L. Zhong, S. Youchao, Research on Maintainability Evaluation Model Based on Fuzzy Theory, Chinese J. Aeronaut. 20(5) (2007) pp. 402-407.

[30] T. L. Saaty, The Analytic Hierarchy Process, McGraw-Hill Inc., New York, 1980.

[31] M. M. Grime, G. Wright, Delphi Method, Wiley StatsRef: Statistics Reference Online, John Wiley \& Sons, Chichester, UK, August 2016, pp. 1-6.

[32] L. Ciani, G. Guidi, G. Patrizi, M. Venzi, System Maintainability Improvement using Allocation Procedures, Proc. of the IEEE International Systems Engineering Symposium (ISSE), 2018, pp. 1-6.

[33] PRC Military Standard GJB/Z 57 - Maintainability Prediction and Allocation Handbook, Beijing, 1994.

[34] Y. Li, Y. Li, C. Lv, An Application of Time Classification in the System Maintenance Allocation BT, Proc. of the 3rd Annual IEEE Prognostics and System Health Management Conference, PHM-2012, 23-25 May 2012, IEEE Reliability Society, Beijing, China.

[35] A. Angrisano, S. del Pizzo, S. Gaglione, S. Troisi, M. Vultaggio, Using Local Redundancy to Improve GNSS Absolute Positioning in Harsh Scenario, Acta IMEKO 7(2) (2018) pp. 16-23.

[36] F. Crenna, G. B. Rossi, A. Palazzo, Measurement of Human Movement under Metrological Controlled Conditions, Acta IMEKO 4(4) (2015) pp. 48-56.

[37] F. Corti, F. Grasso, A. Reatti, A. Ayachit, D. K. Saini, M. K Kazimierczuk, Design of Class-E ZVS Inverter with Loosely-
Coupled Transformer at Fixed Coupling Coefficient, Proc. of the 42nd Annual Conference of the IEEE Industrial Electronics Society, IECON 2016, 2016, pp. 5627-5632.

[38] A. Ayachit, A. Reatti, M. K. Kazimierczuk, Small-Signal Modeling of PWM Dual-SEPIC DC-DC Converter by Circuit Averaging Technique, Proc. of the 42nd Annual Conference of the IEEE Industrial Electronics Society, IECON 2016, 2016, pp. 3606-3611.

[39] E. Petritoli, F. Leccese, M. Botticelli, S. Pizzuti, F. Pieroni, A RAMS Analysis for a Precision Scale-Up Configuration of 'Smart Street' Pilot Site: An Industry 4.0 Case Study, ACTA IMEKO 8(2) (2019) p. 3.

[40] A. Reatti, M. Balzani, PWM Switch Model of a Buck-Boost Converter Operated under Discontinuous Conduction Mode, Proc. of the 48th Midwest Symposium on Circuits and Systems Vol. 1, 2005, pp. 667-670.

[41] G. Fontana, F. Grasso, A. Luchetta, S. Manetti, M. C. Piccirilli, A. Reatti, A New Simulation Program for Analog Circuits Using Symbolic Analysis Techniques, Proc. of the International Conference on Synthesis, Modeling, Analysis and Simulation Methods and Applications to Circuit Design (SMACD), 2015, pp. $1-4$.

[42] R. Paggi, G. L. Mariotti, A. Paggi, F. Leccese, Optimization of Availability Operation via Simulated Prognostics, Proc. of IEEE Metrology for Aerospace (MetroAeroSpace), 2015, pp. 44-48.

[43] L. Ciani, G. Guidi, G. Patrizi, A Critical Comparison of Alternative Risk Priority Numbers in Failure Modes, Effects, and Criticality Analysis, IEEE Access 7 (2019) pp. 92398-92409.

[44] EN 50126-1, Railway Applications - The Specification and Demonstration of Reliability, Availability, Maintainability and Safety (RAMS) - Part 1: Generic RAMS Process, European Committee for Electrotechnical Standardization, CENELEC, 2017.

[45] EN 50126-2, Railway Applications - The Specification and Demonstration of Reliability, Availability, Maintainability and Safety (RAMS) - Part 2: Systems Approach to Safety, European Committee for Electrotechnical Standardization, CENELEC, 2017.

[46] EN 50129, Railway Applications - Communication, Signalling and Processing Systems - Safety Related Electronic Systems for Signalling, European Committee for Electrotechnical Standardization, CENELEC, 2018.

[47] D. Seneviratne, L. Ciani, M. Catelani, D. Galar, Smart Maintenance and Inspection of Linear Assets: An Industry 4.0 Approach, ACTA IMEKO 7(1) (2018) p. 50. 